\title{
Pleurodesis Using Mistletoe Extract Delivered via a Spray Catheter during Semirigid Pleuroscopy for Managing Symptomatic Malignant Pleural Effusion
}

\author{
Jung Seop Eom ${ }^{\mathrm{a}, \mathrm{d}}$ Hyo Yeong Ahn ${ }^{\mathrm{b}}$ Jeong Ha Mok ${ }^{\mathrm{a}}$ Geewon Lee ${ }^{\mathrm{c}}$ \\ Eun-Jung Jo ${ }^{a}$ Mi-Hyun Kim ${ }^{a}$ Kwangha Lee ${ }^{a}$ Ki Uk Kim ${ }^{a}$ Hye-Kyung Park ${ }^{a}$ \\ Min Ki Lee ${ }^{a}$ \\ ${ }^{a}$ Department of Internal Medicine, Pusan National University School of Medicine, Busan, South Korea; \\ ${ }^{b}$ Department of Thoracic and Cardiovascular Surgery, Pusan National University School of Medicine, Busan, \\ South Korea; ' Department of Radiology, Pusan National University School of Medicine, Busan, South Korea; \\ ${ }^{\mathrm{d}}$ Biomedical Research Institute, Pusan National University Hospital, Busan, South Korea
}

For editorial comment see p. 143

\section{Keywords}

Malignant pleural effusion - Mistletoe · Pleurodesis ·

Pleuroscopy

\section{Abstract}

Background: Talc poudrage during thoracoscopy is considered the standard procedure for patients with symptomatic malignant pleural effusion (MPE). Until now, no alternative technique other than talc poudrage for pleurodesis during medical thoracoscopy has been proposed. Liquid sclerosants, such as mistletoe extract, have been sprayed evenly into the pleural cavity during semirigid pleuroscopy for chemical pleurodesis. Objective: We conducted a retrospective study using the database of semirigid pleuroscopy to identify the usefulness of pleurodesis using a mistletoe extract delivered via a spray catheter during semirigid pleuroscopy for symptomatic MPE. Methods: All consecutive patients with symptomatic MPE who underwent semirigid pleuroscopy from October 2015 to September 2016 were registered. The responses were evaluated using chest $\mathrm{X}$ ray or computed tomography 4 weeks after pleurodesis. Results: The study included 43 patients who underwent
() 2017 S. Karger AG, Basel pleurodesis with mistletoe extract via a spray catheter during semirigid pleuroscopy. Complete and partial responses were seen in 21 (49\%) and 19 (44\%) patients, respectively. The median duration of chest tube placement after pleurodesis was 7 days (range 6-8 days) in the 40 patients with complete or partial responses. No cases of severe hemorrhage, empyema formation, respiratory failure, or procedure-related mortality were observed in the subjects at 4 weeks after semirigid pleuroscopy. Conclusion: Pleurodesis with mistletoe extract delivered via a spray catheter during semirigid pleuroscopy is a safe and effective procedure for managing symptomatic MPE.

(c) 2017 S. Karger AG, Basel

\section{Introduction}

According to the current guidelines, patients with symptomatic malignant pleural effusion (MPE), no evidence of trapped lung, and a life expectancy $>1$ month should be managed by either insertion of an intercostal

\section{J.S. Eom and H.Y. Ahn contributed equally to this work.}

Jung Seop Eom, MD 
Fig. 1. Atomizing the liquid agent using a spray catheter.
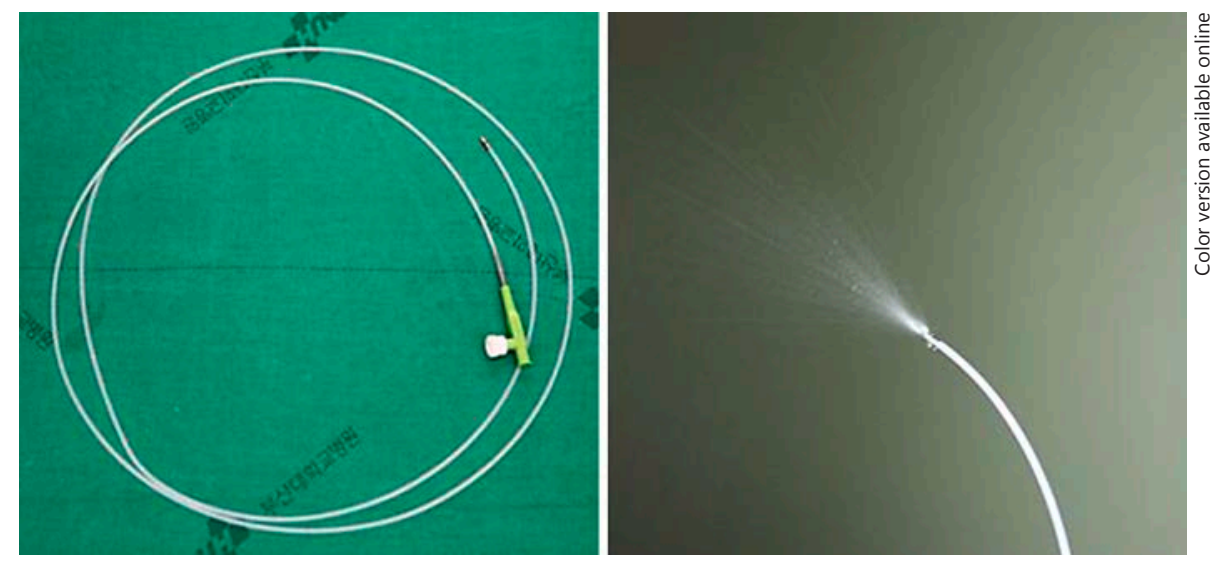

tube or pleurodesis [1-3]. In addition, once pleural effusion drainage and lung re-expansion have been achieved, chemical pleurodesis should be considered to prevent recurrence of MPE $[2,4,5]$. Until now, among the various methods to treat pleurodesis, talc poudrage during thoracoscopy using sterile, large-particle talc is considered the standard procedure for patients with symptomatic MPE [6].

A previous study demonstrated that small-particle talc is associated with acute respiratory distress syndrome or systemic distribution of talc particles [2]. However, graded talc, which generally has a particle size $>15 \mu \mathrm{m}$, is not always available. Moreover, it is difficult to spray graded talc through the $2.8-\mathrm{mm}$ working channel of a semirigid pleuroscope [7]. Unfortunately, no alternative agent or technique has been proposed so far.

The use of a spray catheter was introduced as a unique technique to achieve topical lidocaine anesthesia of the pleura before pleurodesis during semirigid pleuroscopy (Fig. 1) [8]. A sclerosant in liquid form can be sprayed evenly into the pleural cavity using a spray catheter in the same way. In addition, mistletoe extract, which is considered to have anticancer effects, is a potentially useful sclerosant for chemical pleurodesis [9], and one case series on chemical pleurodesis using mistletoe extract delivered via a spray catheter during semirigid pleuroscopy was published recently [10]. However, there is little evidence indicating that chemical pleurodesis, i.e., delivery of mistletoe extract via a spray catheter during semirigid pleuroscopy, is effective and safe. Therefore, we conducted a retrospective study using the database of semirigid pleuroscopy to ascertain the usefulness of chemical pleurodesis using a mistletoe extract delivered via a spray catheter during semirigid pleuroscopy for symptomatic MPE.

\section{Patients and Methods}

Study Population

A retrospective study using the database of semirigid pleuroscopy that included patients treated from October 2015 to September 2016 was performed to investigate the efficacy of chemical pleurodesis using a mistletoe extract delivered via a spray catheter during semirigid pleuroscopy at Pusan National University Hospital (a university-affiliated tertiary referral hospital in Busan, South Korea). All consecutive patients with symptomatic MPE who underwent semirigid pleuroscopy were registered during the study period. Written informed consent was obtained from all study participants before semirigid pleuroscopy, and the study was approved by the Institutional Review Board of Pusan National University Hospital (No. 1612-023-050).

\section{Semirigid Pleuroscopy and Pleurodesis Procedures}

A representative case of chemical pleurodesis using mistletoe extract delivered via a spray catheter (PW-5L-1; Olympus, Tokyo, Japan) during semirigid pleuroscopy is shown in online supplementary Figure 1 (for all online suppl. material, see www. karger.com/doi/10.1159/000481869). All procedures were performed during inpatient hospital stay in the bronchoscopy suite by two respiratory physicians (J.S. Eom and J.H. Mok). Each patient was placed on the operating table in the lateral decubitus position with the affected side upward, and bedside ultrasonography was used to determine the trocar entry site. The patients were connected to blood pressure, pulse oximetry, and continuous electrocardiography monitors [11]. Fentanyl and midazolam were administered intravenously for conscious sedation, and oxygen was supplied via a nasal cannula as necessary during the procedure. The skin was draped in an aseptic fashion with povidone-iodine solution and alcohol. One milliliter of $2 \%$ lidocaine was administered on the skin as local anesthesia, followed by anesthesia of subcutaneous tissue, the adjacent ribs, and parietal pleura with $10 \mathrm{~mL}$ of $2 \%$ lidocaine. A small incision was made at the trocar entry site, and blunt dissection with a Kelly forceps was used to enter the pleural space between the intercostal spaces. A semirigid pleuroscope (LTF-240; Olympus) was introduced through the trocar, and a pleural biopsy was performed under direct visual control. The pleural space was inspected, and all pleural fluid was aspirated. 
Before chemical pleurodesis, $20 \mathrm{~mL}$ of $2 \%$ lidocaine was sprayed into the pleural cavity via a spray catheter, which was introduced through the working channel of the semirigid pleuroscope using the technique of Lee and Colt [8]. Next, $60 \mathrm{mg}$ of mistletoe extract (ABNOBAviscum; ABNOBA GmbH, Pforzheim, Germany) was evenly atomized over the pleural space using a spray catheter (see online suppl. video). At the end of the procedure, an intercostal tube was inserted before wound closure. The tube was connected to an underwater seal device with $-20 \mathrm{~cm} \mathrm{H}_{2} \mathrm{O}$ pressure for $\geq 3$ days. The intercostal tube was removed when effusion drainage was $<150 \mathrm{~mL} /$ day [12].

\section{Response Evaluation after Pleurodesis}

Response evaluation was conducted using chest X-ray or computed tomography (CT) 4 weeks after pleurodesis. According to the World Health Organization criteria [13, 14], no replenishment of effusion at the time of the response evaluation was classified as complete response. Partial response was defined as replenishment of MPE $<50 \%$ of pretreatment effusion and no symptoms. Nonresponse was classified when additional treatment was needed, such as insertion of an intercostal tube, for recurrence of MPE within 4 weeks after chemical pleurodesis.

\section{Results}

\section{Study Population}

During the study period, 47 patients with symptomatic MPE underwent semirigid pleuroscopy. Pleurodesis was not attempted in 4 patients with a trapped lung or in those with suspicion of malignant mesothelioma on chest CT scan for possible pleuropneumonectomy. Finally, 43 patients who received chemical pleurodesis using mistletoe extract delivered via a spray catheter during semirigid pleuroscopy were included in the present study. The baseline characteristics of the patients are presented in Table 1 . The median age of the study patients was 69 years (IQR 62-75 years), and 47\% were male. For increasing severe dyspnea, 13 patients (30\%) received therapeutic thoracentesis at the emergency room before semirigid pleuroscopy. The most common primary site was the lungs (74\%), followed by the breast (7\%), stomach (5\%), and kidneys (5\%). Twenty-nine patients (67\%) received chemotherapy after pleurodesis, including 12 patients $(28 \%)$ with target agents and $3(7 \%)$ with hormone therapy.

\section{Response to Pleurodesis}

Chest radiographs and CT scans were performed for the response evaluation in 15 (35\%) and 28 (65\%) patients, respectively. The median interval between semirigid pleuroscopy and the response evaluation was 31 days (IQR 30-34 days). Overall, complete and partial re-
Table 1. Baseline patient characteristics

\begin{tabular}{lc}
\hline Variables & $\begin{array}{l}\text { Median (IQR) } \\
\text { or } n(\%)\end{array}$ \\
\hline Age, years & $69(62-75)$ \\
Male sex & $20(47 \%)$ \\
Primary cancer & \\
$\quad$ Lung cancer & $32(74 \%)$ \\
Breast cancer & $3(7 \%)$ \\
Stomach cancer & $2(5 \%)$ \\
Renal cell carcinoma & $2(5 \%)$ \\
Mesothelioma & $1(2 \%)$ \\
Gastrointestinal stromal tumor & $1(2 \%)$ \\
Ovarian cancer & $1(2 \%)$ \\
Cholangiocarcinoma & $1(2 \%)$ \\
Effusion drained during procedure, mL & $750(450-1,030)$ \\
Treatment after pleurodesis & $14(33 \%)$ \\
Intravenous cytotoxic chemotherapy & $12(28 \%)$ \\
Target agents & $3(7 \%)$ \\
Hormone therapy & $14(33 \%)$ \\
Supportive care &
\end{tabular}

IQR, interquartile range.

sponses were seen in $21(49 \%)$ and 19 (44\%) patients, respectively. The median duration of chest tube placement after pleurodesis was 7 days (IQR 6-8 days) in 40 patients with a complete or partial response.

Three (7\%) patients were classified into the nonresponder group, and an intercostal tube was inserted to manage recurrent MPE in all these cases. Chemical pleurodesis was performed again by delivering mistletoe extract through the intercostal tube in 2 patients, who finally achieved partial responses. Additional pleurodesis could not be performed in the other patient due to worsening general condition related to rapid tumor progression.

Of the 40 patients who achieved complete or partial responses at 1 month, the response was maintained in 38 (95\%) 3 months after pleurodesis. However, 2 patients (5\%) with a partial response required additional chest tube insertion.

\section{Safety Profile}

No procedure-related mortality or severe complications, including hemorrhage requiring transfusion or intervention, empyema, or respiratory failure, occurred within 4 weeks after semirigid pleuroscopy in any patient. Fever developed in 20 (47\%) patients within $24 \mathrm{~h}$ after the procedure, and all cases spontaneously resolved with or 
without administration of an antipyretic. Analgesics, such as oral rapid-release oxycodone, intranasal fentanyl spray, fentanyl sublingual tablet, or intravenous opioids, were needed in $22(51 \%)$ patients to manage chest pain related to pleurodesis.

\section{Discussion}

In the present study, we found that chemical pleurodesis using mistletoe extract delivered via a spray catheter during semirigid pleuroscopy was effective and safe for managing symptomatic MPE. The overall response rate was $93 \%$, and no serious adverse events related to chemical pleurodesis were observed. Our findings suggest that the technique of atomizing a mistletoe extract evenly into the pleural space using a spray catheter could be an alternative to talc poudrage during semirigid pleuroscopy.

The recent guidelines for chemical pleurodesis for MPE recommend talc as the most effective sclerosant [2, 3]; however, sterile graded talc (particle size $15 \mu \mathrm{m}$ ) is not always available. In addition, it is difficult to atomize talc powder through the working channel of a semirigid pleuroscope under direct visual control. Ishida et al. [7] reported that talc powder could be sprayed into the pleural cavity using a thick guide sheath kit (K-203; Olympus), under direct visual control, introduced through the working channel of a semirigid pleuroscope. A guide sheath originally developed as a disposable silicone passage for radial probe endobronchial ultrasound [15]. Four types of guide sheath kit are available, consisting of a cytology brush, a biopsy forceps, and a guide sheath for transbronchial lung biopsy of peripheral lung lesions. Talc poudrage administered via a thick guide sheath during semirigid pleuroscopy costs $\$ 487$ in South Korea (\$292 for $4 \mathrm{~g}$ of talc and $\$ 195$ for the thick guide sheath kit). On the other hand, the spray catheter was developed as a reusable endoscopicaccessory; thus, themistletoe extract pleurodesis using a spray catheter costs $\$ 76$ in South Korea ( $\$ 76$ for $60 \mathrm{mg}$ of mistletoe extract and $\$ 0$ for the reusable spray catheter).

Previous studies have reported that mistletoe pleurodesis yields a 72-97\% success rate for apposition of the visceral and parietal pleura in patients with MPE $[9,16]$. However, an aqueous solution of mistletoe extract was instilled into the pleural cavity via a chest tube in previous reports. Accordingly, we developed a novel technique to spray the mistletoe extract evenly into the pleural cavity when pleurodesis was performed during thoracoscopy. In the present study, the mistletoe extract was sprayed via a spray catheter during semirigid pleuroscopy and achieved an acceptable overall response rate. Our findings indicate that distributing the mistletoe extract evenly into the pleural cavity with a spray catheter under direct visual control may be a useful method for chemical pleurodesis in patients with MPE, particularly in patients who undergo semirigid pleuroscopy. Additionally, previous studies have suggested that mistletoe extract pleurodesis leads to a decrease in tumor cells and an increase in lymphocytes in the pleural fluid [16, 17]. Although the mechanism of immune response evoked by mistletoe extract pleurodesis remains unclear, mistletoe extract might induce anticancer effects on pleural tumors as well as an inflammatory reaction between the parietal and visceral pleura.

Kennedy et al. [18] reported that the median chest tube duration was 5.6 days after talc pleurodesis via a chest tube. In addition, de Campos et al. [19] demonstrated that the mean chest tube duration after thoracoscopic talc poudrage was 5.6-7.2 days. Recently, the British Thoracic Society guidelines recommended the removal of a chest tube within 1-2 days of sclerosant administration in the absence of excessive fluid drainage ( $>250 \mathrm{~mL} /$ day) [2]. However, the median chest tube duration in the present study was 7 days, which was longer than that for talc pleurodesis. It is possible to apply two hypotheses regarding the long chest tube duration. First, the inflammatory reaction evoked by mistletoe extract might be slower than that evoked by talc pleurodesis. Second, we used relatively strict criteria in the timing of chest tube removal (chest tube removal when the drainage is $<100-150 \mathrm{~mL}$ for two continuous days after pleurodesis). Unfortunately, it is impossible to identify the accurate causal relationship concerning the relatively long chest tube duration after pleurodesis using mistletoe extract in the present study.

This study had several limitations that should be acknowledged. First, it was retrospective and had a relatively small sample size. Although all data were collected prospectively, potential selection bias could have influenced our results. Second, either CT or chest radiographs were used to evaluate the pleurodesis response. Even though the present study was performed using the database of semirigid pleuroscopy, the modality of response evaluation could not be controlled. Although the accuracy of detecting remnant MPE is quite different between chest radiographs and CT scans, the most important factor for classification into the responder (complete or partial response) and nonresponder groups (no response) is the presence of respiratory symptoms, which are related to the recurrence of MPE. Third, the pain scale is a useful 
index to assess the intensity of pain induced by chemical pleurodesis. In addition, the performance status is a helpful marker to understand the characteristics of the study population. Although the database was collected prospectively, the pain scale and performance status variables were not recorded. Finally, our results indicate that $93 \%$ of the overall response rate in chemical pleurodesis using mistletoe extract delivered via a spray catheter during semirigid pleuroscopy is not inferior to that of talc pleurodesis [20, 21]. However, our study did not involve a direct comparison between mistletoe extract and talc pleurodesis. A further prospective randomized controlled trial with a large study population is needed to achieve conclusive results.

\section{Conclusions}

Chemical pleurodesis with mistletoe extract, which was atomized evenly using a spray catheter, was effective and safe during semirigid pleuroscopy when performed by respiratory physicians. Instilling the mistletoe extract into the pleural cavity via a spray catheter can be performed to treat chemical pleurodesis in patients with MPE, particularly when sterile large-particle talc is unavailable.

\section{Financial Disclosure and Conflicts of Interest}

All authors declare no conflict of interest. This work received no funding.

\section{References}

1 Tan C, Sedrakyan A, Browne J, Swift S, Treasure T: The evidence on the effectiveness of management for malignant pleural effusion: a systematic review. Eur J Cardiothorac Surg 2006;29:829-838.

2 Roberts ME, Neville E, Berrisford RG, Antunes G, Ali NJ; BTS Pleural Disease Guideline Group: Management of a malignant pleural effusion: British Thoracic Society Pleural Disease Guideline 2010. Thorax 2010;65 (suppl 2):ii32-ii40.

3 American Thoracic Society: Management of malignant pleural effusions. Am J Respir Crit Care Med 2000;162:1987-2001.

4 Heffner JE: Diagnosis and management of malignant pleural effusions. Respirology 2008;13:5-20.

5 Viallat JR, Rey F, Astoul P, Boutin C: Thoracoscopic talc poudrage pleurodesis for malignant effusions. A review of 360 cases. Chest 1996;110:1387-1393.

6 Janssen JP, Collier G, Astoul P, Tassi GF, Noppen M, Rodriguez-Panadero F, Loddenkemper R, Herth FJ, Gasparini S, Marquette $\mathrm{CH}$, Becke B, Froudarakis ME, Driesen P, Bolliger CT, Tschopp JM: Safety of pleurodesis with talc poudrage in malignant pleural effusion: a prospective cohort study. Lancet 2007; 369:1535-1539.
7 Ishida A, Nakamura M, Miyazawa T, Astoul P: Novel approach for talc pleurodesis by dedicated catheter through flexi-rigid thoracoscope under local anesthesia. Interact Cardiovasc Thorac Surg 2011;12:667-670.

8 Lee P, Colt HG: A spray catheter technique for pleural anesthesia: a novel method for pain control before talc poudrage. Anesth Analg 2007;104:198-200.

9 Cho JS, Na KJ, Lee Y, Kim YD, Ahn HY, Park CR, Kim YC: Chemical pleurodesis using mistletoe extraction (ABNOVAviscum ${ }^{\circledR}$ injection) for malignant pleural effusion. Ann Thorac Cardiovasc Surg 2016;22:20-26.

10 Eom JS, Kim TH, Lee G, Ahn HY, Mok JH, Lee MK: Chemical pleurodesis using mistletoe extracts via spray catheter during medical thoracoscopy for management of malignant pleural effusion. Respirol Case Rep 2017;5: e00227.

11 Lee P, Yap WS, Pek WY, Ng AW: An audit of medical thoracoscopy and talc poudrage for pneumothorax prevention in advanced COPD. Chest 2004;125:1315-1320.

12 Sahn SA: Pleural diseases related to metastatic malignancies. Eur Respir J 1997;10:19071913.

13 Kessinger A, Wigton RS: Intracavitary bleomycin and tetracycline in the management of malignant pleural effusions: a randomized study. J Surg Oncol 1987;36:81-83.

14 World Health Organization: WHO Handbook for Reporting Results of Cancer Treatment. Geneva, World Health Organization Offset Publication, 1979, pp 22-26.
15 Kurimoto N, Miyazawa T, Okimasa S, Maeda A, Oiwa H, Miyazu Y, Murayama M: Endobronchial ultrasonography using a guide sheath increases the ability to diagnose peripheral pulmonary lesions endoscopically. Chest 2004;126:959-965.

16 Stumpf C, Bussing A: Stimulation of antitumour immunity by intrapleural instillation of a Viscum album L. extract. Anticancer Drugs 1997;8(suppl 1):S23-S26.

17 Salzer G: Pleura carcinosis. Cytomorphological findings with the mistletoe preparation Iscador and other pharmaceuticals. Oncology 1986;43(suppl 1):66-70.

18 Kennedy L, Rusch VW, Strange C, Ginsberg RJ, Sahn SA: Pleurodesis using talc slurry. Chest 1994;106:342-346.

19 de Campos JR, Vargas FS, de Campos Werebe E, Cardoso P, Teixeira LR, Jatene FB, Light RW: Thoracoscopy talc poudrage: a 15-year experience. Chest 2001;119:801-806.

20 Shaw P, Agarwal R: Pleurodesis for malignant pleural effusions. Cochrane Database Syst Rev 2004;1:CD002916.

21 Yim AP, Chan AT, Lee TW, Wan IY, Ho JK: Thoracoscopic talc insufflation versus talc slurry for symptomatic malignant pleural effusion. Ann Thorac Surg 1996;62:1655-1658.
Pleurodesis with Mistletoe Extract via Spray Catheter 